\title{
ALIMENTOS TRANSGÊNICOS: RISCOS E QUESTÕES ÉTICAS
}

Maria Alice Garcia ${ }^{1}$

\section{INTRODUÇÃO}

A descoberta da possibilidade de transferir genes de organismos de uma espécie para outra representa, hoje, uma das mais intrigantes ferramentas de que o homem dispõe para desenvolver tecnologias e organismos a partir da ruptura de barreiras entre organismos de diferentes espécies em condições naturais.

A transferência de genes vem sendo utilizada em vários ramos da atividade humana, sendo que na ciência básica e aplicada a agricultura, a medicina e a área farmacêutica representam as que mais têm investido recursos humanos e financeiros e apresentado resultados para o desenvolvimento de novos produtos e processos, muitos deles já comercializados.

A inserção dessa tecnologia no mercado tem, no entanto, gerado muita controvérsia. Se, por um lado, oferece um grande elenco de potenciais aplicações na busca de melhoria da qualidade de vida do ser humano, os produtos até o momento disponibilizados também representam, no estágio atual do conhecimento, a possibilidade de riscos à saúde e ao ambiente. Além das questões ligadas a interesses econômicos das empresas transnacionais de biotecnologia e das suas relações e interferências na política econômica e legislação nacional e internacional sobre transgênicos, os principais focos de discussão concentram-se em questões sobre: monopólios e segurança alimentar, patenteamento da vida, efeitos de liberação de organismos geneticamente modificados (OGMs) no ambiente, incertezas a respeito dos efeitos a médio e longo prazo do consumo de alimentos geneticamente modificados, significado e consequiências da produção de plantas, animais e do próprio homem (ou partes dele) a partir de engenharia genética,

1. Prof. Livre Docente, Instituto de Biologia, Unicamp, SP. CP 6109, 13083-970. Brasil. E-mail: alika@unicamp.br 
e implicações sobre valores éticos e religiosos.

A introdução da tecnologia nuclear e química também não se deu pacificamente. Mas a grande diferença é que hoje a opinião pública está se manifestando na fase inicial da introdução da tecnologia e de seus produtos no mercado. Não podemos dizer que o mesmo teria ocorrido nas décadas de 50 e 60, quando os interesses da população estavam voltados para outros focos. Quando as discussões se concentravam em questões relacionadas à reçonstrução do pós-guerra em vários países europeus e nos desdobramentos catastróficos das crises políticas e instalação de regimes totalitários nos países em desenvolvimento. Um fator decisivo no questionamento da biotecnologia, na forma como se apresenta hoje, é, sem dúvida, o maior nível de consciência a respeito da importância do ambiente e do seu valor, como parte do conceito de qualidade de vida dos seres humanos. Como cidadãos, vivenciamos hoje um momento distinto da nossa história quando comparamos com as décadas de 50 e 60, e é de acordo com as nossas respostas às novas condições que se apresentam e com o grau de consciência e de conhecimentos que continuaremos a intervir para construirmos o futuro que será vivido pelas próximas gerações. Neste sentido, a consciência a respeito do papel do meio ambiente como bem comum e o reconhecimento de nossas relações intra e interespecíficas também para a manutenção da saúde nos fazem questionar as possíveis implicações dessa nova tecnologia.

É com essa percepção de seres de uma espécie que constrói sua própria história, de acordo com o acesso a informações, faz análises, julgamentos e os traduz em atitudes, que me parece interessante discutir essa nova tecnologia: suas potencialidades, seus riscos e a demanda de conhecimentos que se faz notar no momento atual para melhor implementá-la.

Uma vez que a grande polêmica atual está relacionada com alimentos transgênicos, vou concentrar a discussão nas questões da produção de alimentos geneticamente modificados, abordando os seguintes aspectos:

1. Contexto em que a biotecnologia se insere na agricultura.

2. Situação atual de sua implementação no Brasil e no mundo 
3. Riscos associados a OGMs:

a) Plantas resistentes a insetos,

b) Plantas resistentes a doenças,

c) Plantas tolerantes a herbicidas,

d) Animais tratados com hormônio derivado de OGM.

4. Demanda de pesquisa.

5. Conclusões e questões éticas associadas a riscos para esta e gerações futuras.

\section{Contexto em que a biotecnologia se insere na agricultura}

Estamos vivenciando atualmente uma revolução biotecnológica que muitos denominam segunda Revolução Verde. No entanto, o contexto em que ocorre e as bases tecnológicas que as fundamentam são muito diferentes. Os componentes tecnológicos principais que promoveram a Revolução Verde, que se inicia logo após a Segunda Guerra Mundial, derivavam da Química e da Mecânica. Estes componentes eram basicamente insumos químicos e maquinaria, que condicionaram mudanças consideráveis tanto na estrutura como no funcionamento dos agroecossistemas. Mas, além disso, promoveram todo um setor industrial e de serviços que se desenvolveram intensamente, acoplados ao sistema de produção agrícola. A expansão das fronteiras agrícolas e da monocultura em larga escala, assim como redução da diversidade do sistema e a seleção de linhagens genéticas mais adequadas a essa tecnologia são decorrências deste modelo. A homogeneidade favorece tanto a produção em escala como o uso de implementos e insumos. Ocorre também a redução considerável da base biológica do sistema de produção de alimentos e da sua biodiversidade interna. Atualmente, apenas uma dezena de culturas, principalmente arroz, milho, trigo, soja, feijão e batata respondem por 80 a $90 \%$ do total de calorias consumidas no mundo (Brown 1999). No entanto, é inquestionável o aumento de produtividade decorrente da revolução verde. A perda da diversidade na base genética de produção é facilmente evidenciada pelo exemplo do milho no seu próprio centro de origem, o México, onde hoje se cultivam apenas $20 \%$ das variedades 
usadas em 1930. A fragilidade desses sistemas e impactos ambientais e socio-econômicos que promovem são razões suficiente para sérios questionamentos à sua sustentabilidade.

A genética molecular e o desenvolvimento da engenharia genética representam ferramentas bem distintas daquelas que a química e a mecanica ofereceram para a promoção da Revolução Verde. A produção de organismos geneticamente modificados - OGMs - via transferência de genes entre espécies, inclusive de ramos distintos, com vistas à expressão de novos caracteres, é revolucionária em sua base biológica. Diferente da primeira revolução, é a modificação da matéria prima do sistema de produção, a espécie cultivada, que vai arrastar as modificações de parte considerável das demais estruturas associadas ao sistema de produção. No seu extremo, para uma das linhas de desenvolvimento dessa tecnologia, isto significa a possibilidade de concentração na planta cultivada, através de modificações do seu genoma, de grande parte das funções de defesa e de promoção de crescimento, hoje exercidas por insumos exógenos produzidos por setores industriais, promovidos pela revolução verde. É exatamente nessa linha que se concentra a maior parte das pesquisas e de produtos da engenharia genética hoje no mercado. E não é por acaso que os maiores investimentos no setor de biotecnologia agrícola ocorrem concomitantemente a processos de fusões entre companhias de sementes e de agroquímicos.

Essa incorporação de caracteres fenotípicos na semente, em substituição à parafernália de defesa e promotora de crescimento das plantas cultivadas, implica, no entanto, mudanças complexas cujas conseqüências para o ambiente, para a biodiversidade faunística e florística, e para a saúde humana, devem ser consideradas de maneira muito criteriosa, uma vez que estamos lidando com: 1) as bases do sistema alimentar da nossa espécie; 2) as bases do sistema terrestre de produção primária, hoje representada por uma extensão de cerca de $3 / 5$ da área terrestre utilizável, ocupada com plantio de espécies cultivadas. Assim, mesmo possíveis vantagens econômicas decorrentes da simplificação de processos produtivos podem ser discutíveis em uma análise mais aprofundada das suas conseqüências a médio e longo prazo. 
Em vários aspectos, os tipos de riscos para a saúde humana $\mathrm{e}$ impactos sobre os demais componentes bióticos e abióticos e a percepção desses riscos também são distintos quando comparamos os dois momentos: o da revolução verde e o da revolução biotecnológica. No entanto, o não cumprimento da promessa dos transgênicos, tais como produtos ambientalmente limpos e seguros e até mesmo algumas contradições, são muito evidentes. $\mathrm{O}$ fato de a biotecnologia voltada a produtos ter-se desenvolvido mais rapidamente nos setores vinculados à produção de insumos para o primeiro modelo tecnológico, gerou como primeiros produtos, para o mercado agrícola, o que podemos chamar de produtos biotecnológicos sujos; ou seja OGMs que mantêm a dependência em relação à tecnologia anterior e que trazem consigo os riscos de ambas as tecnologias. É o caso dos OGMs para tolerância a herbicidas.

\section{Situação atual}

Em que estágio nos encontramos quanto ao desenvolvimento e implementação dessa tecnologia em sistemas agrícolas? Considerando os últimos anos (1986-2000), mais de 30.000 testes de campo com OGM para distintas espécies foram realizados em mais de 45 países, inclusive o Brasil. O cultivo comercial de OGMs é liderado pelos Estados Unidos, que representam $64 \%$ da área total plantada, seguida pela China e pela Argentina. Há tendência de aumento da área cultivada com transgênicos, que passou de 2,8 milhões de hectares em 1986 para 12,8, em 1997, e para 30 milhões de hectares em 2000.

Snow \& Palma (1997) listam 53 espécies de plantas OGM estudadas ou já produzidas comercialmente. Pertencem a 21 famílias e suas modificações encaixam-se nas seguintes categorias: 29 espécies modificadas para tolerância a herbicidas, 31 modificadas para resistência a doenças, 20 para resistência a insetos e 25 com outras características.

Quando analisamos os dados da Aphis, verificamos que cerca de $75 \%$ das solicitações para liberação no meio ambiente nos EUA referemse a OGMs para tolerância a herbicidas, resistentes a insetos e/ou doenças. Apenas $25 \%$ das solicitações referem-se a plantas modificadas para alguma característica agronômica relacionada a tolerância a estresse, ca- 
pacidade de fixação de $\mathrm{N}$ ou resistência a seca ou geada.

No Brasil, todas as solicitações apresentadas até o momento estão na categoria de tolerância a herbicidas e/ou resistência a doenças ou insetos. De acordo com o programa de grandes multinacionais ligadas à produção de transgênicos, o Brasil é um dos países previstos para produção em larga escala, especialmente de soja, milho e algodão tolerantes a herbicida e resistentes a insetos (Lappé \& Bailey, 1998).

Atualmente, o plantio comercial da soja transgênica tolerante a herbicida obteve parecer favorável da CTNBio (Comissão Técnica Nacional de Biosegurança, órgão consultivo do Ministério de Ciência e Tecnologia). No entanto, uma ação judicial impetrada pelo IDEC (Instituto de Defesa do Consumidor) e apoiada pelo Ibama (órgão do Ministério do Meio Ambiente) e várias ONGs, embargou o plantio, alegando a ausência de dados sobre impactos ambientais. Assim, o cultivo comercial continua proibido, mas a entrada de produtos transgênicos para ração acaba de ser autorizada, com a importação de milho geneticamente modificado da Argentina. No Brasil a rotulagem é obrigatória. As normas de rotulagem devem ser divulgadas nos próximos dias. A lei proibe a comercialização no País de produtos geneticamente modificados sem a devida identificação, mas há dificuldades em garantir o cumprimento da lei por deficiência dos mecanismos de fiscalização.

Na Europa, embora algumas espécies de OGM sejam cultivadas, há grande resistência a OGMs e produtos delas derivados. A tradição de pequena produção aliada à história recente da vaca louca são apontados como causas dessa maior cautela dos europeus quando comparados com os americanos. No entanto, ultimamente, mesmo nos EUA a resistência a esses produtos tem aumentado levando a EPA e FDA a revisar suas recomendações.

A Associação Médica Britânica, em uma revista bastante conceituada, The Economist, manifestou-se a favor de uma moratória sem data de término, alegando o princípio da precaução, que deve ser tomado quando se trata de saúde humana. A argumentação principal que fundamenta a posição dos médicos britânicos é a ausência de dados confiáveis sobre a segurança do cultivo e da ingestão continuada de OGMs e derivados sobre a saúde humana. 
No Brasil, a mídia tem apresentado matérias sobre transgênicos, mas, na maioria das vezes, essas matérias exprimem mais opiniões de grupos de interesse e não prestam esclarecimentos à população. $\mathrm{O}$ acesso a informação e a discussão mais bem fundamentada vem ocorrendo em foros promovidos por Universidades e algumas ONGs, que vëm analisando a implementação da tecnologia e discutindo os riscos a ela associados. Em especial, ao risco de, em um futuro próximo, estarmos nos alimentando com transgêmcos sem sequer sabermos disso.

\section{Riscos Associados a Transgênicos}

Afinal, que riscos têm sido apontados como associados aos transgênicos?

Uma lista bastante completa é apresentada pela Union of Concerned Scientists e foi publicada pela Third World Network em 1995. Apesar dos avanços ocorridos nos últimos anos, os riscos continuam os mesmos.

O primeiro risco deriva da concepção de que um gene se associa a uma única característica, que se transfere apenas essa característica, que ficaria completamente sob controle. Não se considera que a expressão do gene pode variar com o ambiente genômico, celular, extracelular e mesmo externo. Em especial, no caso de escape do gene, este entrará em contato com outros genomas, com manifestação e efeitos imprevisíveis. Além disso, o genoma de diferentes populações também difere e está sujeito a diferentes processos que poderão alterar taxas de mutação e recombinação produzindo alterações ao nível de indivíduo, população e até mesmo de comunidades de plantas, animais e microorganismos. Em particular, é preocupante o fato de, havendo risco de escape, se este ocorrer, a recuperação do gene ser impossível. No caso de genes que aumentam a aptidão do portador, ou seja, sua capacidade de deixar descendentes, sua dispersão é inevitável.

A poluição genética é diferente da de qualquer outra natureza, pois tem a possibilidade de se difundir por reprodução, reduzindo a probabilidade de controle por eliminação da fonte do poluente e fugindo completamente ao controle, o que representa um risco a ser analisado. 
Considerando os três diferentes tipos de OGMs e produtos de OGM mais comuns na atualidade, podemos analisar alguns dos seus principais riscos.

\section{a) Plantas Resistentes a Insetos}

O gene para resistência que vem sendo mais utilizado é o que codifica para a produção de proteína tóxica da bactéria Bacillus thuringiensis. Esta bactéria (Bt) há quase um século vem sendo utilizada como agente de controle biológico de insetos, uma vez que é letal, especialmente para grupos de lepidópteros (mariposas e borboletas) e coleópteros (besouros). A inserção de genes para toxina de Bt em plantas cultivadas se traduz em efeitos equivalentes aos causados por sobredosagem de agrotóxicos (Van Emden, 1999).

O primeiro risco apontado neste caso é o de impacto da toxina, quando expressa na planta, sobre espécies não alvo. Polinizadores, predadores e parasitóides de insetos podem ser afetados de diferentes maneiras. Há evidencias de que afideos (pulgões) são capazes de sequestrar a toxina e adquirir proteção contra coleóperos Coccinellidae (joaninhas) predadores. Coccinelídeos tratados com estes afideos tiveram menor taxa de fecundidade e longevidade do que os tratados com afideos alimentados em plantas não transgênicas (Birch et al., 1998). Um outro exemplo é observado para o crisopídeo, Chrysoperla carnea um neuróptero predador, cujas larvas tiveram taxa de mortalidade maior do que o dobro da observada quando alimentadas com presas criadas em plantas nãotransgênicas (Hilbeck et al. 1998). Os efeitos sobre o terceiro nível trófico podem ainda promover desequilíbrios populacionais em espécies pragas que, reconhecidamente, não são sensíveis ao Bt. É o caso de Spodoptera frugiperda, mariposa cujo $\mathrm{pH}$ do tubo digestivo não é adequado às condições de alcalinidade necessária para a absorção da toxina (Oarcia et al. 1982). Esta espécie é normalmente controlada por dipteros (moscas) e himenópteros parasitóides (microvespas) (Garcia, 1979, 1991) que, se afetados pela toxina, poderão reduzir seu impacto sobre a população da praga, amplificando os problemas por ela causados.

Experimentos do tipo publicado na Nature sobre possíveis im- 
pactos da toxina em espécies não alvo, no caso da borboleta monarca (Losey et al. 1999), uma espécie carismática, principalmente nos EUA, demonstram que há risco de impacto sobre populações não alvo, que pode desencadear um efeito em cascata sobre a comunidade de animais e de plantas. No caso, essa borboleta é o principal herbívoro que se alimenta de Asclepias, um gênero de plantas invasoras altamente tóxicas para o gado e que é comum em áreas ruderais e bordas de cultivo.

Duas espécies pragas de cultivos desenvolveram resistência à toxina do Bt quando submetidas a forte pressão de seleção; é o caso das mariposas Ostrinia nubilalis e Heliothis virescens (vide Tabashnik, 1994, Liu et al., 1999, Van Emden, 1999). O desenvolvimento de resistência em insetos pode levar ainda a potenciais saltos de hospedeiros. A ampliação do espectro de dieta em espécies com potencial eruptivo, ou para explosões populacionais, representa riscos consideráveis da constituição de superpragas e de extinção de espécies silvestres com alto grau de endemismo, comprometendo a biodiversidade.

Outro tipo de impacto, que vem sendo pouco abordado, mas muito relevante, é o efeito das toxinas de $\mathrm{Bt}$, quando aumenta em concentração e permanece por longo período no solo. Donegan e colaboradores (1997) observaram mudanças na composição e densidade das espécies de microrganismos do solo associados a restos de cultivos transgênicos de algodão e de batata. Os efeitos sobre a fauna benéfica detritivora foram observados pelo mesmo grupo em trabalho com tabaco. Demonstraram a persistência de um inibidor de proteinase em restos de tabaco transgênico incorporado ao solo, até 57 dias após a incorporação. Houve mudanças da fauna, que passou a ser dominada por nematóides fungívoros. Colêmbolos foram reduzidos significativamente.

Assim, podemos nos perguntar quais são os efeitos sobre a fauna benéfica e detritívora do solo nas nossas condições? Quais os efeitos sobre a microflora decompositora? O processo de decomposição poderá ser comprometido? Que tipos de mudança comunitária poderão ocorrer no sistema edáfico? Como a fertilidade do solo poderá ser modificada em decorrência das alterações nesses processos? Não temos respostas para essas questões. 
Marvier \& Kareiva (1999) apontam ainda como risco a possibilidade de transferência de genes para resistência a insetos para plantas ruderais, via hibridação. Neste caso, seus estudos de simulação para dinâmica populacional dessas espécies de plantas, quando livres dos seus insetos herbívoros, demonstram alta probabilidade de incidência de novas plantas pragas a médio e longo prazo.

Finalmente, um risco significativo é o da eliminação de Bacillus thuringiensis como uma das mais importantes ferramentas de controle biológico para agricultores que adotam práticas distintas da convencional, tais como os agicultores orgânicos. Uma vez que a pressão de seleção será intensa quando o uso do OGM com a toxina do Bt se generalizar, o desenvolvimento de resistência em espécies pragas será uma questão de tempo, conforme já demonstrado a $O$. nubilalis e H.virescens. Neste caso, o agricultor que não adote essa tecnologia será adversamente afetado, pois o controle biológico de pragas com Bt não mais será efetivo. Além da questão ecológica, está portanto colocada uma questão de conflito de interesses.

\section{b) Plantas Resistentes a Doenças.}

Plantas resistentes a doenças têm sido produzidas especialmente via inserção de genes para a produção de proteína do capsídeo, que é a cápsula protêica que envolve o material genético de vírus.

A possibilidade de modificações nos grupos de vírus associados a plantas pode ocorrer por duas vias:

a) genes que codificam para a proteína do vírus, presentes no genoma da planta, podem ser capturados por um vírus infectante diferente e, por recombinação, gerar um novo vírus.

Neste caso, inclusive vírus não patogênicos podem vir a se tornar patogênicos e ter alterada a sua via de transmissão e espectro de hospedeiros, podendo vir a causar doenças e a infectar plantas que anteriormente não infectava.

b) transencapsidação, processo que ocorre quando um vírus que invade uma planta se reproduz e fica encapsulado com a proteína de outro vírus que ocorria na planta. Neste caso também pode haver alteração 
da via de transmissão, inclusive convertendo vírus que não eram transmitidos por insetos em arbovírus, além de mudança em patogenicidade e espectro de hospedeiro. Um exemplo de transencapsidação em OGM é registrado para tabaco em laboratório.

O vírus do mosaico do pepino, em $40 \%$ dos casos em que infectou fumo trasgênico, apresentou evidência de trasencapsidação com a proteína do capsídeo do vírus do mosaico da alfafa, presente no OGM (Krinisky \& Wrube, 1996).

Steinbrecher (1996) relata que novas linhagens de vírus têm sido obtidas a partir de infecção em OGMs resistentes a doenças. Luteovírus têm sido usados na produção dessas plantas. Um outro grupo de vírus, os Umbravírus, dependem deste primeiro grupo para se dispersar. $\mathrm{O}$ risco de ampliação de doenças causadas por Umbravírus, em função da maior oferta de genes para Luteovírus, não tem sido considerado.

É em especial no grupo de plantas transgênicas que o risco de escape de genes para espécies próximas representam alto risco de impacto à biodiversidade e aos recursos genéticos.

Sabemos que as dinâmicas populacionais de diferentes espécies são mediadas por fatores dependentes e independentes de densidade, mas que fatores bióticos, em especial, patógenos, representam, muitas vezes, os fatores chave para a regulação. Sementes, plântulas e indivíduos adultos podem sofrer altas taxas de mortalidade em função de patógenos. Genes para resistência a patógenos, se transferidos, via hibridação, para espécies próximas, que hoje são inócuas, podem tornálas mais aptas, ampliar suas populações e, eventualmente, convertêlas em novas pragas.

Gosto de dar o exemplo do tabaco no Sul do Brasil porque é cultura produzida intensamente nessa região e para a qual já existe solicitação de liberação no meio ambiente junto à CTNBio.

Nicotiana, grupo bastante variável quanto ao cariótipo, em espécies com diferentes números de cromossomos. Mas é também um grupo muito promíscuo. A polinização de muitas de suas espécies é feita por mariposas da família Sphingidae, insetos robustos e com grande capacidade de vôo a longas distâncias. A possibilidade de transferência de genes 
para resistência a patógenos para espécies aparentadas a partir do cultivo de tabaco transgênico é provavelmente uma questão de tempo. Há, portanto, o risco de termos, via hibridação, a seleção de linhagens resistentes a doenças e com potencial invasor de cultivos e de ambientes naturais. Dependendo das condições em que esse processo ocorrer é ainda possível sugerir um impacto sobre a biodiversidade via eliminação de espécies endêmicas em áreas onde essas novas pragas encontrem condi̧̧ões favoráveis para sua expansão e competição com espécies autóctones.

\section{2) Plantas Tolerantes a Herbicidas}

Os impactos desses OGMs podem-se manifestar a partir de:

- Desenvolvimento de resistência nas invasoras submetidas a um tipo particular de herbicida de maneira continuada. A seleção de Senna spp. em cultivos de soja comum é uma evidência disso. Mais de 100 espécies de invasoras são listadas por Holt (1993) como resistentes a herbicidas. Atualmente este número é certamente ainda maior. $\mathrm{O}$ uso intensivo de herbicidas de amplo espectro selecionará mais rapidamente as espécies invasoras resistentes. Para a Austrália já são citadas cinco espécies de invasoras, entre as quais Cirsium arvensis, resistente ao glifosato, herbicida que estará entre os mais usados nos cultivos transgênicos.

1. Impacto do herbicida. Embora os herbicidas estejam entre os agroquímicos menos tóxicos para a fauna, deixam resíduos no solo por tempos variáveis e podem causar anomalias. Bromoxil, por exemplo, é absorvido pela pele e é um dos principais causadores de dermatite em agricultores. Glifosato é também tóxico para a fauna aquática e do solo, em especial predadores como aranhas, besouros carabídeos, coccinelideos e ácaros. Uma vez que os herbicidas tendem a se acumular nas frutas e tubérculos, a ampliação do seu uso também representa maior risco para a saúde humana.

Espécies transgênicas como invasoras. Embora a maioria dos OGMs dificilmente poderiam vir a se tomar problema desse tipo, o fato de 11 entre as 18 principais espécies invasoras no mundo serem aparentadas 
de espécies cultivadas (Hohn et al. 1977), permite levantar esta possibilidade de risco, em especial para ambientes naturais como reservas biológicas.

4. Criação de super-invasoras. Entre as espécies mais citadas como possíveis super-invasoras estão Sorghum bicolor e Oriza sativa. Provavelmente a espécie de sorgo $S$. halepense é derivada de $S$. bicolor e $S$. propingunun,que são invasoras. No caso do arroz, o arroz vermelhoé, na realidade, da mesma espécie quẹ o arroz cultivado e a passagem do gene para resistência a herbicida não teria barreira alguma para ser transferido para o arroz vemelho (Garcia,1999). Mas o exemplo mais claro do potencial de criação de super-invasoras a partir de hibridação de espécies silvestres com OGMs é o caso de Brassica napus, que, embora tenha 19 cromossomos $(2 n=38)$ teve o gene para resistência transferido para Brassica campestris, que tem $10(2 n=20)$ cromossomos (Jorgensen \& Andersen, 1995). Assim, mesmo que a frequência do evento seja muito baixa, sob forte pressão de seleção haverá fixação da característica que resulte em maior aptidão no ambiente. Híbridos de canola, girassol e cucurbitáceas são facilmente produzidos por polinização via insetos. Espécies polinizadas pelo vento são particularmente problemáticas. $\mathrm{O}$ arroz vermelho, uma das principais invasoras em arroz irrigado, certamente tornar-se-á resistente em poucas gerações.

\section{d) Animais tratados com hormônio derivado de OGM}

Esse hormônio, já comercializado desde a década de 80 , recebe o nome de BGH (bovine growth hormone). Sua origem são os Estados Unidos e suas maiores produtoras são a Monsanto e a Eli Lilly Corporation.

O hormônio é produzido a partir de bactéria modificada com o gene de bovino responsável pela produção do hormônio na glândula pituitária. Ele aumenta a produção de leite em vacas em até $30 \%$, com consumo de alimento até 6\% maior do que o normal (Krinsky \& Wrubel, 1996).

Entre os riscos associados ao uso do TSH, como também é chamado o hormônio assim produzido, estão a produção de mastite em vacas e a demanda de maior consumo de antibióticos que passam para o 
leite. Esse hormônio foi autorizado no Brasil em 1990, não tem rótulo especial como derivado de transgênico, e é amplamente utilizado.

\section{Demanda de Pesquisa}

Em nome da própria segurança, os testes de campo não são planejados para avaliação de riscos. Neles evita-se a dispersão de pólen, propágulos e se garante a eliminação dos restos de cultura transgênica. Este é um protocolo para segurança do teste, mas nada informa sobre os riscos de cultivo em larga escala do transgênico. Outros experimentos, levantamentos e monitoração a campo e em laboratório são essenciais para gerar as informações necessárias. É indispensável, por exemplo, que se avaliem:

Espécies aparentadas aos OGM, sua distribuição e biologia, Probabilidades de hibridação do OGM com espécies aparentadas, Fluxo gênico,

Respostas evolutivas de híbridos e de suas interações no ecossistema, Resposta do OGM e de suas interações a longo prazo, Efeitos do OGM sobre espécies não alvo (animais, microorganismos,

biota do solo),

Efeito do uso de herbicida de largo espectro em larga escala, Efeitos potenciais sobre a saúde humana a médio e longo prazo.

\section{Conclusões e questões éticas associadas a riscos}

Estamos vivenciando um período de grande modificação na forma de produção de alimentos e outras matérias primas para a sociedade humana. No entanto, da maneira como essas modificações vêm se processando, as inovações biotecnológicas para a agricultura, até o momento, não têm produzido nada significativamente distinto em termos de beneficio para a humanidade que justifique os riscos de sua implementação rápida e desprovida de uma avaliação detalhada de custos e benefícios para esta e gerações futuras. Altieri (1998) apresenta um conjunto de razões por que a biotecnologia não garantirá a segurança alimentar, não protegerá o ambiente e não reduzirá a pobreza noTerceiro Mundo. Além disso, nada se sabe a respeito da possibilidade de efeitos da ingestão 
continuada de transgênicos e/ou derivados a médio e longo prazo sobre a saúde humana. No entanto, circunstâncias econômicas poderão impor a toda a população a ingestão desses alimentos.

Uma vez que o conceito de risco pode ser enunciado como o produto do grau de dano possível pela probabilidade desse dano ocorrer, é necessário analisar até que ponto conhecemos as duas variáveis dessa equação para poder avaliar o significado desses riscos. Outro aspecto relevante, é considerar o direito de todos de avaliar e decidir quando devemos correr qualquer risco. Afinal, quando é que um cidadão se submete a um risco? Podemos considerar três circunstâncias em que corremos risco: 1) quando, de acordo com nossos princípios e valores, avaliamos que a possibilidade de beneficios compensa o risco; 2) quando, também por uma questão de princípios ou questão moral ou de sentimento, acreditamos que devemos correr o risco; 3) quando o risco nos é imposto. No caso dos alimentos transgênicos é importante que avaliemos o significado da imposição desses riscos para esta e gerações futuras. Como espero ter deixado claro, há muitas questões a serem respondidas antes que OGMs possam ser cultivados de forma responsável e com riscos mínimos para a biodiversidade e para o homem. O princípio da precaução deve ser considerado.

A realidade é que a promessa da biotecnologia não se cumpriu na área de alimentos, uma vez que os produtos que hoje chegam ao mercado não trazem nenhum tipo de vantagem em qualidade para o consumidor e tampouco são mais baratos. As possíveis vantagens para o produtor também são questionáveis. Transgênicos não são mais produtivos do que os não-transgênicos (Lappé \& Baiiey 1998). Trata-se muito mais de uma corrida comercial. $\mathrm{O}$ interesse em recuperar rapidamente os investimentos de grandes corporações e de garantir mercados futuros de sementes faz com que esses produtos sejam emprurrados goela abaixo de governos e da população, desconsiderando a demanda de pesquisas que garantam a biossegurança, em relação à saúde e meio ambiente, atropelando os debates e a legislação.

A quem cabe financiar a produção de informações necessárias para avaliação de riscos? Teoricamente às empresas detentoras da maior 
parte dessa tecnologia. No entanto, é necessário garantir a confiabilidade dos dados produzidos. Portanto, instituições isentas deverão desenvolver projetos de pesquisa de médio e longo prazo para analisar as questões aqui mencionadas. Atualmente, porém, no Brasil, estamos vivendo uma situação de atropelo, mas é necessário que se exijam os estudos adequados antes da liberação dos produtos biotecnológicos. Cabe ainda ressaltar que, na sua forma atual, os produtos biotecnológicos apenas reforçam o modelo agrícola baseado em insumos e na monocultura em larga escala; um modelo que vem sendo intensamente questionado quanto à sua sustentabilidade ecológica, social e econômica.

A biotecnologia oferece, porém, perspectivas bem distintas das atuais se dirigida para a produção de OGMs com outros atributos de interesse agronômico, mas, da mesma forma, perguntas como as alinhadas acima deverão ser adequadamente respondidas. Creio que cabe, em especial, a instituições públicas, quando têm em vista a adoção dessas novas tecnologias, orientação da pesquisa científica também na direção de avaliação de riscos. Isto é indispensável para promover de maneira adequada a evolução dos processos produtivos da nossa sociedade em maior consonância com uma concepção de co-existência da espécie humana com outras espécies, e com um conceito sobre o qual muito se fala e pouco se faz, o de sustentabilidade.

\section{REFERENCIAS BIBLIOGRÁFICAS}

ALTLERI, M A., 1998. The Enviromnental Risks of Transgenic Crops: an Agroecological Assessment. AgBiotech News and Information, 10:105-410.

BIRCH, A.N.E.; L.E. GOEGHEGAN; W.E.N. MAJERUS; J.W. McNICHOL; C. HACKETT; A.M.R. GATEHOUSE \& J.A. GATEHOUSE, 1998. TriTrophic Interactions Involving Pest Aphids, Predatory Two Spot Ladybirds and Transgenic Potatoes Expressing Snowdrop Lectin for Aphid Resistance. Mollecular Breeding, 5:75-83.

BROWN, R.L., 1999. Feeding Nine Bilion, pl 15-132. In: State Of The World. L.R.BROWN, C. FLAVIN \& II. FRENCH (Eds). W.W.Norton 
\& Company, New York.

DONEGAN, K.K., R.J. SEIDLER, V.J F1ELAND, D.L. SCHALLER, C.J. P"L.M. GANIO, D.M. CARDWELL \& Y. STEINBERGER., 1997. Decomposition of Genetically Engineered Tobacco under Field Conditions: Persistence of the Proteinase Inhibitor. 1 Product and Effects on Soil Microbial Respiration and Protozoa, Nematode And Microarthropod Populations. Journal of Applied Ecology, 34:767-777. GARCIA, M.A., 1979. Potencialidade de Alguns Fatores Bióticos e Abióticos na Regulação Populacional de Spodoptera frugiperda (Lepidoptera: Noctuidae). Campinas. Tese de Mestrado. Universidade Estadual de Campinas.

GARCIA, M.A.; M. SIMÕES \& M.E.M. HABIB., 1982. Possible Reasons of Resistance in Larvae of Spodoptera frugiperda (Abbot \& Smith, 1797) Infected by Bacillus thuringiensis var. kurstaki. Revista de Agricultura, 57:215-222.

GARCIA, M.A., 1991. Arthropod in a Tropical Com Field: Effects of Weeds and Insecticides on Community Composition, p.619-633. In: P. PRICE; T.M. LEWINSOHN; G.W. FERNANDES \& W.W. BENSON (eds.). Plant-Animal Interactions: Evolution Ecology in Tropical and Temperate Regions. John Wiley \& Sons, N.York. GARCIA, M.A., 1999. Convergências entre Controle Químico, Biológico e Biotecnologia para o Manejo de Plantas Invasoras: Reflexões sobre Ciência e Tecnologia. Ambiente e Sociedade, 3/4:177-186. HILBECK A.; M. BAUNGARTNER; P.M. FRIED \& F. BIGLER., 1998. Effects of Transgenic Bacillus thuringiensis Corn-Fed Prey on Mortality and Development Time of Immature Chrysopela carnea (Neuroptera: Crysopidae). Environmental Entomology, 27:480-487.

HOLM, L.G.; D.L. PLUCKENETT; J V. PANCHO \& J P HERBERGER, 1977. The World's Worst Weeds Distribution and Biology. The University Press of Hawaii, Honolulu.

HOLT, J.S; S.B. POWLES \& J.A.M. HOLTUM, 1993. Mechanisms and Agronomic Aspects of Herbicide Resistance. Annual Review Plant Physiology Plant Molecular Biology, 44:203-229.

JORGENSEN, R.B. \& B ANDERSEN, 1995. Spontaneous Hybridization 
Between Oilseed Rape (Brassica napus) and Weed B.campesfris (Brassicaceae): a Risk of Growing Genetically Modified Oilseed Rape. American Journal of Botany, 81:1169-1175.

KRJIMSKY, 5 \& R. WRUBEL. 1996. Agricultural Biotechnology and the Enviromnent: Science, Policy and Social Issues. University of Illinois Press, Urbana and Chicago.

LAPPÉ, M \& B. BAILEY, 1998. Against the Grain; Biotechnology and

the Corporate Takeover of our Food. Common Courage Press, Monroe, ME.

LIU, Y.B.; B.E. TABASHNIK; T.J. DENNEHY; A.L. PATLN \& A.C. BARDETT, 1999. Development Time and Resistance to Bt. Crops. Nature, 400:519.

LOSEY, J.E.; L.S. RAYOR \& M.E. CARTER, 1999. Transgenic Pollen Harms Monarch Larvae. Nature, 399:214

MARVIER, M. \& P. KAREIVA, 1999. Extrapolating from Field Experiments that Remove Herbivores to Population-Level Effects of Herbivore Resistance Transgenes. Proceedings of Workshop on Ecological Effects of Pest Resistance Genes in Managed Ecosystems. January 31/February 3, P.L. TRAYNOR \& J.H. WESTWOOD (eds), Virginia Polytechnic Institute and State University Blacksburg, Virginia, p. 57-64.

SNOW, A.A. \& P.M. PALMA, 1997. Commercialization of Transgenic

Plants: Potential Ecological Risks. Bioscience, 47:86-96.

STEINBRECHER, R.A., 1996. From Green to Gene Revolution: the

Environmental Risks of Genetically Engineered Crops. The Ecologist, 26:273-282.

TABASHNICK, B.E., 1994. Evolution of Resistance to Bacillus thuringiensis. Annual Review of Entomology, 39:47-79.

UNION OF CONCEMED SCIENTISTS, 1995. The Need for Veater Regulation and Control of Genetic Engineering. Third World Network, Penang, Malaysia.

VAN EMIDEN, H.F., 1999. Transgenic Host Plant Resistance to Insects - Some Reservations. Annals of the Entomological Society of America, 92:788-797. 